\title{
Solid Acid Catalysts Based on Niobium \\ and Zirconium Oxides for Hydrolysis-Dehydration \\ of Cellulose Into Glucose and 5-Hydroxymethylfurfural. Impact of Preparation Technique \\ on Catalytic Properties
}

\author{
Nikolay V. Gromov*a,b, \\ Irina S. Yakovleva ${ }^{a}$, Lubov A. Isupova ${ }^{a}$, \\ Valentin N. Parmona and Oxana P. Taran ${ }^{\mathrm{a}, \mathrm{c}, \mathrm{d}}$ \\ ${ }^{a}$ Boreskov Institute of Catalysis $S B R A S$ \\ Novosibirsk, Russian Federation \\ ${ }^{b}$ Novosibirsk State Technical University \\ Novosibirsk, Russian Federation \\ 'Institute of Chemistry and Chemical Technology SB RAS \\ FRC "Krasnoyarsk Scientific Center SB RAS" \\ Krasnoyarsk, Russian Federation \\ ${ }^{d}$ Siberian Federal University \\ Krasnoyarsk, Russian Federation
}

Abstract. The impact of the preparation techniques of niobium oxide and two-component systems based on niobium and zirconium oxides on the catalytic properties was studied in the one-pot hydrolysisdehydration of cellulose into glucose and 5-hydroxymethylfurfural. Cellulose transformation was performed in an autoclave at $180{ }^{\circ} \mathrm{C}$ under argon atmosphere. The most promising methods for the preparation of solid catalysts were found to be microwave heating and mechanical activation. Glucose and 5-hydroxymethylfurfural can be produced with total yield equal to $20-21 \%$ in the presence of catalysts prepared using these techniques.

Keywords: catalyst, niobium oxide, zirconium oxide, cellulose, glucose, 5-hydroxymethylfurfural, hydrolysis-dehydration.

(C) Siberian Federal University. All rights reserved

This work is licensed under a Creative Commons Attribution-NonCommercial 4.0 International License (CC BY-NC 4.0).

* Corresponding author E-mail address: gromov@catalysis.ru 
Citation: Gromov N.V., Yakovleva I.S., Isupova L.A., Parmon V.N., Taran O.P. Solid acid catalysts based on niobium and zirconium oxides for hydrolysis-dehydration of cellulose into glucose and 5-hydroxymethylfurfural. Impact of preparation technique on catalytic properties, J. Sib. Fed. Univ. Chem., 2020, 13(2), 283-296. DOI: 10.17516/1998-2836-0182

\title{
Твердые кислотные катализаторы
}

на основе оксидов ниобия и циркония

для гидролиза-дегидратации целлюлозы

в глюкозу и 5-гидроксиметилфурфурол.

Влияние метода приготовления

на каталитические свойства

\author{
Н.В. Громов ${ }^{\mathrm{a}, \boldsymbol{0}}$, И.С. Яковлева ${ }^{\mathrm{a}}$, \\ Л.А. Исупова ${ }^{\mathrm{a}}$, В.Н. Пармон ${ }^{\mathrm{a}}$, О.П. Таран ${ }^{\mathrm{a}, \mathrm{B}, \mathrm{r}}$ \\ ${ }^{a}$ Институт катализа им. Г.К. Борескова СО РАН \\ Российская Федерачия, Новосибирск \\ ${ }^{\sigma}$ Новосибирский государственный технический университет \\ Российская Федерачия, Новосибирск \\ ${ }^{6}$ Институт химии и химической технологии СО РАН \\ ФИЦ «Красноярский научный центр СО РАН» \\ Российская Федерачия, Красноярск \\ ${ }^{2}$ Сибирский федеральный университет \\ Российская Федераиия, Красноярск
}

Аннотация. Изучено влияние методов приготовления однокомпонентных ниобий оксидных катализаторов и двухкомпонентных систем на основе оксидов ниобия и циркония на их эффективность в одностадийном процессе гидролиза-дегидратации целлюлозы в глюкозу и 5-гидроксиметилфурфурол. Превращение целлюлозы изучено в автоклаве в чистой горячей воде при $180{ }^{\circ} \mathrm{C}$ в атмосфере аргона. Полученные данные позволяют сделать вывод о том, что наиболее активными являются твердые катализаторы на основе оксидов ниобия и циркония, приготовленные методами СВЧ-обработки и механической активации. В присутствии катализаторов, синтезированных с применением таких методов, глюкоза и 5-гидроксиметилфурфурол могут быть получены с суммарным выходом до 20-21 \%.

Ключевые слова: катализатор, оксид ниобия, оксид циркония, целлюлоза, глюкоза, 5-гидроксиметилфурфурол, гидролиз-дегидратация.

Цитирование: Громов, Н.В. Твердые кислотные катализаторы на основе оксидов ниобия и циркония для гидролизадегидратации целлюлозы в глюкозу и 5-гидроксиметилфурфурол. Влияние метода приготовления на каталитические свойства / Н.В. Громов, И.С. Яковлева, Л.А. Исупова, В.Н. Пармон, О.П. Таран // Журн. Сиб. федер. ун-та. Химия, 2020. 13(2). C. 283-296. DOI: $10.17516 / 1998-2836-0182$ 


\section{Введение}

Высокий уровень негативного воздействия на окружающую среду технологий, основанных на ископаемых источниках сырья и энергии (нефть, газ, уголь), обусловливает значительный интерес к поиску и развитию технологий переработки альтернативных ресурсов. Среди последних нужно особенно отметить возобновляемую растительную биомассу, преимуществом которой выступает ее практическая неисчерпаемость, а также положительное воздействие производства растительной биомассы на экологическую обстановку за счет связывания диоксида углерода в процессе фотосинтеза [1-7]. Основным компонентом растительной биомассы является целлюлоза [8-9], поэтому исследование возможности переработки данного полисахарида в ценное химическое сырье и компоненты топлив представляется особенно перспективным. Целлюлоза, выделенная из растительного сырья, отходов сельскохозяйственной и лесоперерабатывающей отраслей промышленности, может быть переработана в глюкозу путем гидролиза $[1,2,8]$. Гидролиз-дегидратация целлюлозы делает возможным получение 5-гидроксиметилфурфурола (5-ГМФ) - кислородсодержащего циклического соединения, считающегося перспективной молекулой-платформой (platform molecule) для производства топлив, полимеров и пр. [10].

В настоящий момент общепринятыми подходами к переработке биомассы являются кислотнокатализируемый и ферментативный методы. Следует подчеркнуть, что растворимые кислотные катализаторы гидролиза полисахаридов оказывают сильное коррозионное воздействие на оборудование, а для ферментативных катализаторов характерны высокая стоимость, низкие скорости превращений и существенные ограничения по температуре использования. Необходимость применения катализаторов и высоких температур для превращения целлюлозы обусловлена нерастворимостью полисахарида в воде и жесткой устойчивой кристаллической структурой, препятствующей переработке целлюлозы [11]. Применение традиционных методов превращения целлюлозы приводит также к образованию большого количества экологически опасных сточных вод, проблемам с разделением растворимых продуктов и катализаторов, а также трудностям повторного использования катализаторов.

Применение твердых кислотных катализаторов для деполимеризации целлюлозы позволит избежать перечисленных недостатков традиционных процессов. К настоящему времени предложен ряд различных твердых кислотных катализаторов, таких как ионообменные смолы $[12,13]$, различные углеродные материалы [12], нанесенные наночастицы металлов, цеолиты [14], соли гетерополикислот [15], оксиды металлов [16]. Среди перечисленных каталитических систем особый интерес вызывают катализаторы на основе нерастворимых в горячей воде оксидов циркония и ниобия. Благодаря высокому содержанию кислотных центров на поверхности такие катализаторы эффективны в процессах гидролиза полисахаридов, а также дегидратации фруктозы и глюкозы в 5-ГМФ [14, 17, 18]. Ранее нами была показана возможность применения рентгеноаморфного оксида ниобия, нанесенного на поверхность оксида циркония, $\mathrm{NbO}_{\mathrm{x}} / \mathrm{ZrO}_{2}$, в качестве катализатора гидролиза-дегидратации активированной микрокристаллической целлюлозы в глюкозу и 5-ГМФ [19]. Максимальные выходы глюкозы и 5-ГМФ составили 22 и 16 мас. \% соответственно.

Условия приготовления (химическая природа предшественника, температура обработки, способ приготовления и т.п.) могут оказывать существенное влияние на свойства получаемых ка-

$$
-285-
$$


тализаторов. Chareonlimkun и соавторы, исследуя активность $\mathrm{TiO}_{2}$, чистого $\mathrm{ZrO}_{2}$ и сульфатированного серной кислотой при $70^{\circ} \mathrm{C} \mathrm{ZrO}$, показали, что использование в качестве предшественников нитратов цирконила и титанила вместо соответствующих хлоридов, а также прокаливание прекурсора при более низких температурах позволяют получать более активные оксидные катализаторы [20]. Авторам удалось добиться выхода 5-ГМФ из целлюлозы 12 мас. \% при $250{ }^{\circ} \mathrm{C}$.

Целью данной работы стало исследование влияния методов приготовления оксида ниобия и двухкомпонентных катализаторов на основе оксидов ниобия и циркония на их каталитическую активность в процессе гидролиза-дегидратации целлюлозы в глюкозу и 5-ГМФ. В работе применяли следующие методы приготовления: метод сложноэфирных полимерных предшественников с последующим отжигом (Пекини), комбинация методов СВЧ-обработки, мехактивации и терморазложения предшественников.

\section{Экспериментальная часть}

Химические реактивы и материальь

Катализаторы готовили с использованием в качестве предшественников оксинитрата цирконила $\mathrm{ZrO}\left(\mathrm{NO}_{3}\right) \cdot \mathrm{xH}_{2} \mathrm{O}\left(99.5 \%\right.$, Acros Organics) и оксалата ниобия $\mathrm{Nb}\left(\mathrm{HC}_{2} \mathrm{O}_{4}\right)_{5} \cdot \mathrm{xH}_{2} \mathrm{O}(99.95 \%$, Acros Organics). В качестве стандартов ВЭЖХ анализа использовали следующие химические реактивы: 5-гидроксиметилфурфурол (95\%, Acros), D-фруктоза (98 \%, Sigma-Aldrich), D-манноза (98 \%, Sigma-Aldrich), D-глюкоза (99 \%, Sigma-Aldrich), D-целлобиоза (98 \%, Alfa Aesar). Для приготовления всех катализаторов и растворов была взята деионизованная вода, очищенная на установке Milli-Q (Millipore, Франция). В качестве инертного газа в реакторе использовался аргон (99.998 \%, ГОСТ 10157-70, ОАО «Сибтехгаз», Россия).

В качестве субстрата использовали целлюлозу (ЗАО «Вектон», Россия), активированную в планетарной мельнице дискретного действия «Pulverizette 5» («Fristch», Idar-Oberstein, Германия) в течение 40 мин по методике, описанной нами ранее [19, 21]. Исследование размера частиц активированной целлюлозы проводили с помощью оптического микроскопа «Zeiss Axiostar plus», Германия), оснащенного фотокамерой [19, 21]. Размер частиц активированной целлюлозы составлял $22.3 \pm 8$ мкм, степень кристалличности $36 \%$. Рентгенофазовый анализ образцов целлюлозы проводили с помощью дифрактометра BrukerD8 Advabced (Германия) [19].

\section{Приготовление катализаторов}

Оксиды ниобия и двухкомпонентные катализаторы на основе оксидов ниобия и циркония готовили с использованием комбинаций методов СВЧ-обработки, механохимической активации, терморазложения, высокотемпературного отжига, прокаливания, а также методом сложноэфирных полимерных предшественников с последующим отжигом (метод Пекини).

Механохимическая обработка предшественников проходила в шаровой центробежно-планетарной мельнице АПФ-5 с водным охлаждением. Время механической обработки (мехактивации) варьировали от 2 до 4 мин, соотношение массы активируемого порошка и массы шаров составляло 1:10. Ускорение, достигаемое в барабанах мельницы, 40 g. Загрузка образца в каждом из барабанов составляла 15 г.

Для СВЧ-обработки использовали установку на основе высокодобротного прямоугольного резонатора для проведения высокотемпературных химических реакций в поле излучения

$$
-286-
$$


в микроволновом диапазоне с уровнем падающей СВЧ-мощности 300 Вт [22]. Для обработки кварцевую пробирку с образцом (внешний диаметр пробирки 19-20 мм, навеска образца составляла $\sim 1.5$ г) помещали в максимум магнитной или электрической компоненты поля. Резонатор с установленным реактором настраивали на рабочую частоту и подавали СВЧмощность от магнетрона (рабочая частота $2450 \pm 100$ МГц, мощность энерговыделения в образце до $100 \mathrm{~B} / \mathrm{cm}^{3}$, скорость нагрева хорошо поглощающих образцов до $100{ }^{\circ} \mathrm{C} / \mathrm{c}$ и более). В экспериментах в условиях СВЧ-нагрева с разным уровнем мощности температуру в реакторе регистрировали с использованием пирометра фирмы Raytek, который позволяет измерять температуру внешней поверхности кварцевой стенки реактора.

Двухкомпонентный катализатор на основе оксидов ниобия и циркония готовили также методом Пекини [23]. Для приготовления двухкомпонентной системы использовали гидрат оксинитрата цирконила $\mathrm{ZrO}\left(\mathrm{NO}_{3}\right)_{2} \cdot \mathrm{xH}_{2} \mathrm{O}$ и гидрат оксалата ниобия $\mathrm{Nb}\left(\mathrm{HC}_{2} \mathrm{O}_{4}\right)_{5} \cdot \mathrm{xH}_{2} \mathrm{O}$, этиленгликоль (ч), лимонную кислоту (чда), этилендиамин (ЭД) в следующих мольных соотношениях: лимонная кислота : этиленгликоль : этилендиамин : $\mathrm{Zr}+\mathrm{Nb}$ ) $=3,75: 11,25: 3,75: 1$. Этиленгликоль и лимонную кислоту использовали в качестве комплексообразователей, этилендиамин добавляли как дополнительный комплексообразователь. Лимонную кислоту растворяли в этиленгликоле в соотношении лимонная кислота : этиленгликоль $=1: 3$ при перемешивании на водяной бане при $60{ }^{\circ} \mathrm{C}$. Параллельно в 30 мл дистиллированной воды растворяли кристаллогидрат нитрата циркония при перемешивании на водяной бане, затем в него добавляли кристаллогидрат оксалата ниобия и перемешивали до полного растворения. В смешанный раствор вливали раствор лимонной кислоты в этиленгликоле. При постоянном перемешивании без водяной бани добавляли этилендиамин, происходил разогрев раствора и изменение его цвета на темно-желтый. Полученный раствор выдерживали при $50{ }^{\circ} \mathrm{C}$ в течение 3 сут для удаления избытка растворителя из осадка. Затем осадок фильтровали, полученное вещество прокалили при $450{ }^{\circ} \mathrm{C}$ в течение 4 ч.

\section{Физико-химические методы исследования катализаторов}

Текстурные характеристики катализаторов исследовали методом низкотемпературной адсорбции $\mathrm{N}_{2}$ при минус $204{ }^{\circ} \mathrm{C}$ на установке ASAP-2400 (Micrometritics, CША). Bce образцы предварительно дегазировали в вакууме при $130-150{ }^{\circ} \mathrm{C}$. Площадь поверхности рассчитывали по модели БЭТ и уравнению STSA. Распределение пор по размерам оценивали на основании расчетов методами QSDFT и NLDFT.

Фазовый состав катализаторов исследовали методом РФА на рефрактометре Bruker D8 (Германия).

Для оценки кислотных характеристик катализаторов определяли $\mathrm{pH}$ водных суспензий, содержащих материал в количестве 10 г/л. Для определения $\mathrm{pH}$ суспензии навеску катализатора 45 мг помещали в 4.5 мл воды, отдували аргоном. Значения $\mathrm{pH}$ регистрировали через определенные промежутки времени с помощью рН-метра Анион-4100 (Новосибирск, Россия) до достижения постоянного значения $\mathrm{pH}$ суспензии.

Для определения стабильности полученных катализаторов в гидротермальной среде проводили их гидротермальные испытания. Для этого в автоклав помещали 450 мг катализатора, 45 мл воды. Автоклав закрывали и продували аргоном 6 раз для удаления воздуха.

$$
-287-
$$


Включали перемешивание и нагрев. Гидротермальные испытания проводили при интенсивном перемешивании 1500 об/мин механической мешалкой типа пропеллер с магнитным приводом и температуре $180{ }^{\circ} \mathrm{C}$ в течение 3 ч. Затем автоклав остужали до комнатной температуры, катализатор отделяли от раствора центрифугированием. Растворы после испытаний исследовали на содержание атомов циркония и ниобия методом атомно-эмиссионной спектроскопии с индуктивно связанной плазмой (АЭС-ИСП) на приборе PERKIN-ELMER OPTIMA 4300.

\section{Испытания катализаторов}

в реакции гидролиза-дегидратации иеллюлозы

Гидролиз целлюлозы проводили при температуре $180{ }^{\circ} \mathrm{C}$ и давлении аргона $1 \mathrm{MPa} \mathrm{в} \mathrm{ав-}$ токлаве высокого давления (Autoclave Engineers, USA) при интенсивном перемешивании (1500 об/мин) и температуре $180{ }^{\circ} \mathrm{C}$ по методике, описанной нами ранее [19, 24]. Содержание целлюлозы и катализатора составляло 10 г/л. В автоклав помещали 450 мг катализатора, 450 мг целлюлозы и 45 мл воды. Автоклав закрывали и продували аргоном 6 раз для удаления воздуха. Включали перемешивание и нагрев. После достижения температуры реакции $180{ }^{\circ} \mathrm{C}$ (время достижения этой температуры составляет примерно 20 мин) отбирали пробу и этот момент считали за начало реакции. В ходе реакции из автоклава периодически отбирали пробы реакционной смеси для анализа.

Анализ содержания продуктов в реакционной смеси проводили методом ВЭЖХ на хроматографе Prominence LC-20 (Shimadzu, Япония), оборудованном рефрактометрическим и диодноматричным детекторами. Анализ на сахара проводили на колонке Rezex RPMMonosaccharide $\mathrm{Pb}^{2+}$, термостатированой при $70{ }^{\circ} \mathrm{C}$; для анализа кислот использовали колонку Rezex ROA-Organic Acids (Phenomenex, 300 мм $\times 5.0$ мм), термостатированную при $40{ }^{\circ} \mathrm{C}$. В качестве элюентов применяли подаваемую со скоростью 0,6 мл/мин деионизированную воду, приготовленную на установке Milli-Q (Millipore, Франция), или 1.25 мМ водный раствор серной кислоты соответственно.

Расчет выходов продуктов гидролиза целлюлозы проводили в мольных процентах ( \%) по уравнению (1) [25]:

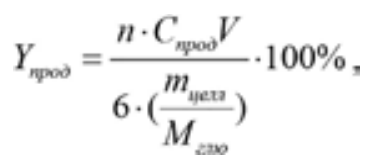

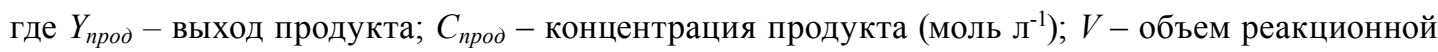
смеси (л); $n$ - количество углерода в молекуле продукта; $m_{\text {челл }}-$ масса целлюлозы (г); $M_{\text {глю }}-$ молярная масса остатка глюкозы в целлюлозе (162 г·моль $\left.{ }^{-1}\right)$.

\section{Результаты и обсуждение}

Исследование катализаторов физико-химическими методами

В соответствии с методиками приготовления, описанными в экспериментальной части, получены три образца оксида ниобия, а также четыре образца двухкомпонентных катализаторов на основе оксидов ниобия и циркония (табл. 1): 
Таблица 1. Методы приготовления оксидных катализаторов

Table 1. Preparation techniques of oxide catalysts

\begin{tabular}{|c|c|c|}
\hline $\begin{array}{c}\text { № } \\
\text { образца }\end{array}$ & Шифр образца & Метод приготовления \\
\hline 1 & $\mathrm{Nb}_{2} \mathrm{O}_{5}-\mathrm{T}-450$ & $\begin{array}{l}\text { Прокаливание (терморазложение) оксалата ниобия } \mathrm{Nb}\left(\mathrm{HC}_{2} \mathrm{O}_{4}\right)_{5} \cdot \mathrm{xH}_{2} \mathrm{O} \text { при } \\
450{ }^{\circ} \mathrm{C} \text { в течение } 4 \text { ч }\end{array}$ \\
\hline 2 & $\mathrm{Nb}_{2} \mathrm{O}_{5}-\mathrm{CBЧ}-5$ & \multirow{2}{*}{$\begin{array}{l}\mathrm{CBЧ-обработка} \mathrm{оксалата} \mathrm{ниобия} \mathrm{Nb}\left(\mathrm{HC}_{2} \mathrm{O}_{4}\right)_{5} \cdot \mathrm{xH}_{2} \mathrm{O} \text { в течение } 5 \text { или } 13 \text { мин } \\
\text { при мощности } 35-80 \mathrm{BT}\end{array}$} \\
\hline 3 & $\mathrm{Nb}_{2} \mathrm{O}_{5}-\mathrm{CBY}-13$ & \\
\hline 4 & $\begin{array}{l}14 \% \mathrm{Nb}_{2} \mathrm{O}_{5^{-}} \\
\mathrm{ZrO}_{2-4-900}\end{array}$ & $\begin{array}{l}\text { мехактивация гидрата оксинитрата цирконила } \mathrm{ZrO}\left(\mathrm{NO}_{3}\right)_{2} \cdot \mathrm{xH}_{2} \mathrm{O} \text { и оксалата } \\
\text { ниобия } \mathrm{Nb}\left(\mathrm{HC}_{2} \mathrm{O}_{4}\right)_{5} \cdot \mathrm{xH}_{2} \mathrm{O} \text { в течение } 4 \text { мин с последующим отжигом при } \\
900{ }^{\circ} \mathrm{C} \text { в течение } 9 \text { ч }\end{array}$ \\
\hline 5 & $\begin{array}{l}2.8 \% \mathrm{Nb}_{2} \mathrm{O}_{5^{-}} \\
\mathrm{ZrO}_{2}-2-450\end{array}$ & $\begin{array}{l}\text { мехактивация гидрата оксинитрата цирконила } \mathrm{ZrO}\left(\mathrm{NO}_{3}\right)_{2} \cdot \mathrm{xH}_{2} \mathrm{O} \text { и оксалата } \\
\text { ниобия } \mathrm{Nb}\left(\mathrm{HC}_{2} \mathrm{O}_{4}\right)_{5} \cdot \mathrm{xH}_{2} \mathrm{O} \text { в течение } 2 \text { мин с последующим прокаливанием } \\
\text { при } 450{ }^{\circ} \mathrm{C} \text { в течение } 4 \text { ч }\end{array}$ \\
\hline 6 & $\begin{array}{l}4.5 \% \mathrm{Nb}_{2} \mathrm{O}_{5-}^{-} \\
\mathrm{ZrO}_{2}-2-450\end{array}$ & $\begin{array}{l}\text { мехактивация гидрата оксинитрата цирконила } \mathrm{ZrO}\left(\mathrm{NO}_{3}\right)_{2} \cdot \mathrm{xH}_{2} \mathrm{O} \text { и оксалата } \\
\text { ниобия } \mathrm{Nb}\left(\mathrm{HC}_{2} \mathrm{O}_{4}\right)_{5} \cdot \mathrm{xH}_{2} \mathrm{O} \text { в течение } 2 \text { мин с последующим прокаливанием } \\
\text { при } 450{ }^{\circ} \mathrm{C} \text { в течение } 4 \text { ч }\end{array}$ \\
\hline 7 & $\begin{array}{l}4.5 \% \mathrm{Nb}_{2} \mathrm{O}_{5^{-}} \\
\mathrm{ZrO}_{2}-\text { Пек }\end{array}$ & метод Пекини \\
\hline
\end{tabular}

Образец 1. Оксид ниобия $\mathrm{Nb}_{2} \mathrm{O}_{5}$ - получен прокаливанием реактива оксалата ниобия $\mathrm{Nb}\left(\mathrm{HC}_{2} \mathrm{O}_{4}\right)_{5} \cdot \mathrm{xH}_{2} \mathrm{O}$ при $450{ }^{\circ} \mathrm{C}$ в течение 4 ч.

Образцы 2 и 3. Оксиды $\mathrm{Nb}_{2} \mathrm{O}_{5}$ - получены СВЧ-обработкой оксалата ниобия $\mathrm{Nb}\left(\mathrm{HC}_{2} \mathrm{O}_{4}\right)_{5} \cdot \mathrm{xH}_{2} \mathrm{O}$ в течение 5 или 13 мин соответственно при мощности СВЧ-излучения 35$80 \mathrm{BT}$.

Образец 4. Двухкомпонентный материал на основе оксидов ниобия и циркония состава $14 \% \mathrm{Nb}_{2} \mathrm{O}_{5}-86 \% \mathrm{ZrO}_{2}$ приготовлен мехактивацией смеси гидрата оксинитрата цирконила $\mathrm{ZrO}\left(\mathrm{NO}_{3}\right) \cdot \mathrm{xH}_{2} \mathrm{O}$ и оксалата ниобия $\mathrm{Nb}\left(\mathrm{HC}_{2} \mathrm{O}_{4}\right)_{5} \cdot \mathrm{xH}_{2} \mathrm{O}$ в течение 4 мин с последующим отжигом при $900{ }^{\circ} \mathrm{C}$ в течение 9 ч.

Образцы 5 и 6. Двухкомпонентные материалы на основе оксидов ниобия и циркония состава $2.8 \% \mathrm{Nb}_{2} \mathrm{O} 5-97.2 \% \mathrm{ZrO}_{2}$ и $4.5 \% \mathrm{Nb}_{2} \mathrm{O}_{5}-95.5 \% \mathrm{ZrO}_{2}$ получены мехактивацией смеси гидрата $\mathrm{ZrO}\left(\mathrm{NO}_{3}\right)_{2} \cdot \mathrm{xH}_{2} \mathrm{O}$ и $\mathrm{Nb}\left(\mathrm{HC}_{2} \mathrm{O}_{4}\right)_{5} \cdot \mathrm{xH}_{2} \mathrm{O}$ в течение 2 мин с последующим прокаливанием при $450{ }^{\circ} \mathrm{C}$ в течение 4 ч.

Образец 7. Двухкомпонентный материал на основе оксидов ниобия и циркония состава $4.5 \% \mathrm{Nb}_{2} \mathrm{O}_{5}-95.5 \% \mathrm{ZrO}_{2}$ приготовлен методом Пекини.

Катализаторы исследованы набором физико-химических методов анализа. Текстурные характеристики образцов изучены методом низкотемпературной адсорбции азота (табл. 2). Все приготовленные катализаторы характеризуются отсутствием микропор и незначительным объемом мезопор (кроме $4.5 \% \mathrm{Nb}_{2} \mathrm{O}_{5}-\mathrm{ZrO}_{2}$-Пек, образец 7). В широком диапазоне варьируется величина удельной площади поверхности (от 1 до 109 м²/г). По величине удельной поверхности оксидные материалы можно разделить на две группы. Наименьшей величиной удельной поверхности характеризуются оксиды ниобия, приготовленные методами терморазложения и СВЧ-обработки (табл. 2, образцы 1-3). Применение методов Пекини и механической активации предшественников с последующим прокаливанием или отжигом при $450{ }^{\circ} \mathrm{C}$ позволяет полу-

$$
-289-
$$


чить двухкомпонентные материалы с величиной удельной поверхности до 86-109 м²/г. Однако отжиг катализатора при $900{ }^{\circ} \mathrm{C}$ в течение 9 ч (табл. 2, образец 4) приводит к существенному уменьшению его поверхности (7 $\left.\mathrm{m}^{2} / \Gamma\right)$.

Фазовый состав оксидных материалов, исследованный методом РФА, отличается заметным разнообразием и очень зависит от способа приготовления катализатора (табл. 2). Образец оксида ниобия, полученный терморазложением (табл. 2, образец 1), состоит преимущественно из моноклинной фазы с примесью орторомбической. Образцы оксидов ниобия, приготовленные с применением СВЧ-излучения (образцы 2 и 3) также имеют рентгеноаморфную структуру с небольшими примесями кристаллических фаз (табл. 2). Смешанный оксид $14 \% \mathrm{Nb}_{2} \mathrm{O}_{5}$ $\mathrm{ZrO}_{2}$-4-900 (табл. 2, образец 4) обладает фазовым составом, характерным для смешенного оксида (рис. 1). Кроме того, в нем присутствуют небольшие количества фаз $\mathrm{ZrO}_{2}$ с моноклинной и $\mathrm{Nb}_{2} \mathrm{O}_{5}$ с орторомбической и моноклинной структурами. Смешанные оксиды (табл. 2, образцы 5,6 ), приготовленные с использованием мехактивации предшественников, содержат моноклинную фазу оксида циркония, а образец, приготовленный методом Пекини $4.5 \% \mathrm{Nb}_{2} \mathrm{O}_{5}$ $\mathrm{ZrO}_{2}$-Пек (табл. 2, образец 7), - смесь моноклинной и тетрагональной фаз $\mathrm{ZrO}_{2}$. Оксид ниобия в образцах 5, 6 и 7 находится в рентгеноаморфном состоянии. Интересно отметить, что схожий фазовый состав наблюдался нами в предыдущей работе, в которой катализаторы $\mathrm{ZrO}_{2}$ были допированы небольшим количеством ниобия (менее 4 \%) [19].

Для определения кислотных свойств оксидных материалов определяли $\mathrm{pH}$ суспензий, содержащих катализатор в количестве 10 г/л (табл. 2). В целом катализаторы показали умеренные кислотностные свойства (значения $\mathrm{pH}$ суспензии находятся в диапазоне 6-7.5). Однако рентгеноаморфные катализаторы на основе оксидов ниобия, приготовленные с применением СВЧ-излучения (образцы 2 и 3), оказались кислее других образцов, причем величина кислотности возрастала с увеличением времени обработки предшественника. Наименьшие значения рН суспензии составили 5.1 и 4.3 для образцов 2 и 3 соответственно.

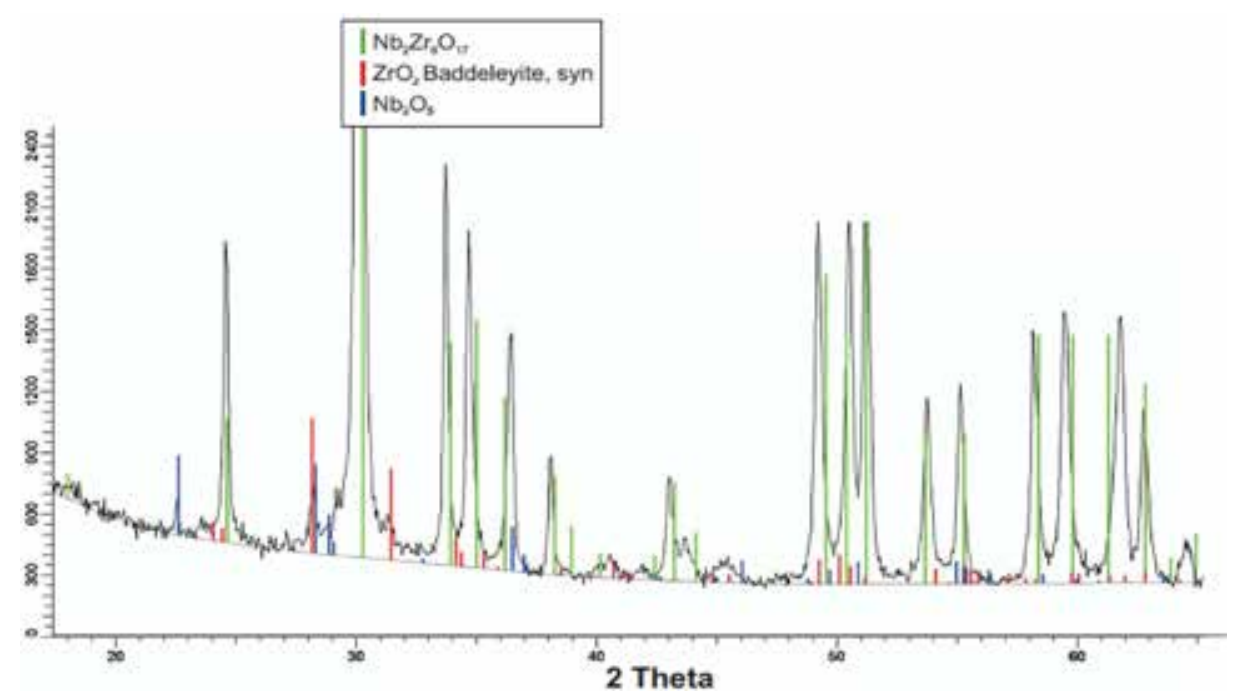

Рис. 1. Рентгенограмма катализатора $14 \% \mathrm{Nb}_{2} \mathrm{O}_{5}-\mathrm{ZrO}_{2}-4-900$ (образец 4)

Fig. 1. X-ray pattern of $14 \% \mathrm{Nb}_{2} \mathrm{O}_{5}-\mathrm{ZrO}_{2}-4-900$ catalyst (sample 4) 


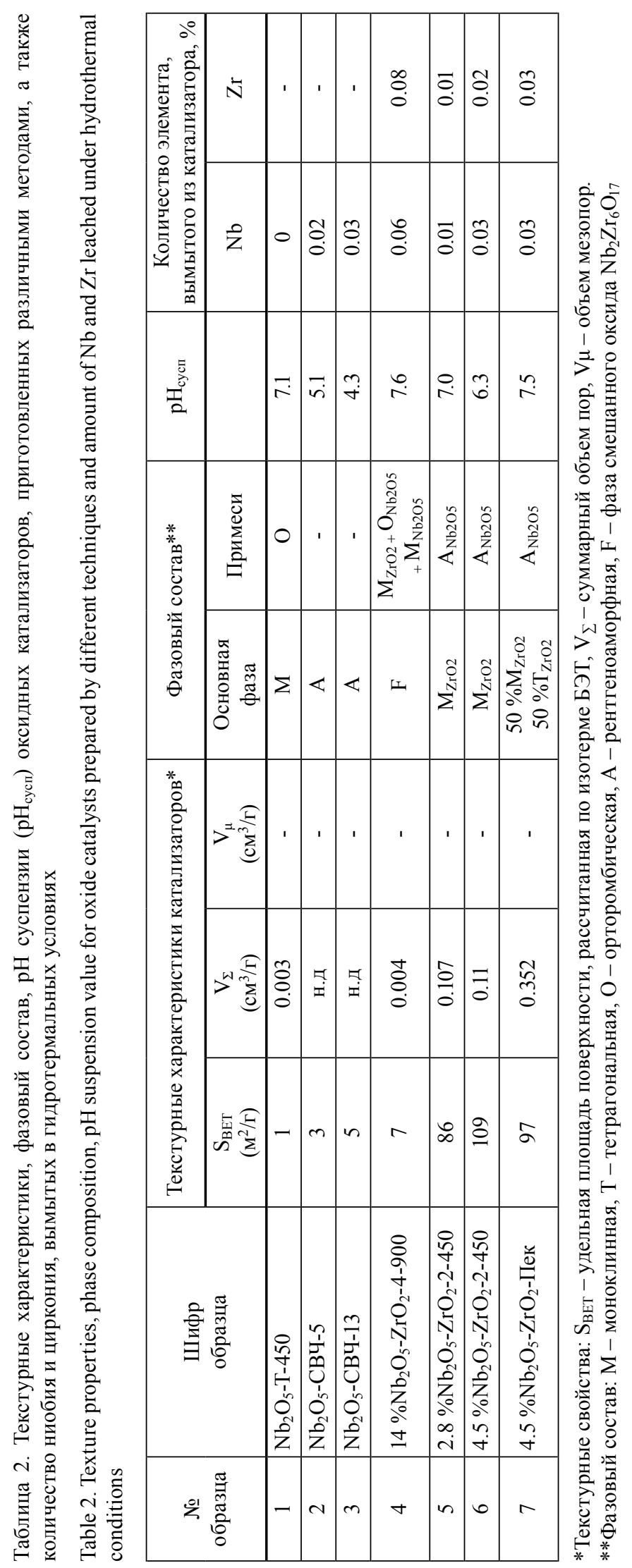


Процесс деполимеризации целлюлозы в водной среде требует применения довольно жестких условий проведения реакции, а именно высоких температур, давления. Поэтому кроме обычных требований высокой активности и селективности к твердым катализаторам предъявляется требование высокой стабильности в агрессивной гидротермальной реакционной среде. Для определения стабильности приготовленных катализаторов на основе оксидов циркония и ниобия проведены гидротермальные испытания при $180^{\circ} \mathrm{C}$ в течение 3 ч. После окончания гидротермальной обработки реакционный раствор исследовали методом АЭС-ИСП на наличие ионов $\mathrm{Nb}$ и Zr. Результаты исследований, приведенные в табл. 2, демонстрируют высокую стабильность разработанных каталитических систем, так как степень вымывания компонентов не превышала $0.06 \%$.

Гидролиз-дегидратация целлюлозы в присутствии оксида ниобия

и двухкомпонентных катализаторов на основе и оксидов ниобия, и циркония

Приготовленные катализаторы на основе оксида ниобия и двухкомпонентных систем на основе оксидов ниобия и циркония испытаны в процессе гидролиза-дегидратации целлюлозы в автоклаве при $180^{\circ} \mathrm{C}$. Методом ВЭЖХ анализа реакционных растворов зарегистрировано образование следующих продуктов: целлобиозы, глюкозы, фруктозы, маннозы, 5-ГМФ, фурфурола, муравьиной и левулиновой кислот. Основными конечными, а также целевыми продуктами реакции являются глюкоза и 5-ГМФ. Выходы целевых продуктов реакции, полученные при испытании катализаторов, приготовленных различными методами, представлены на рис. 2 . Среди образцов оксидов ниобия катализатор $\mathrm{Nb}_{2} \mathrm{O}_{5}$-T-450 (образец 1) продемонстрировал заметную каталитическую активность. Суммарный выход глюкозы и 5-ГМФ достиг $13 \%$. Интересно отметить, что активность этого катализатора достаточно высока, несмотря на низкую

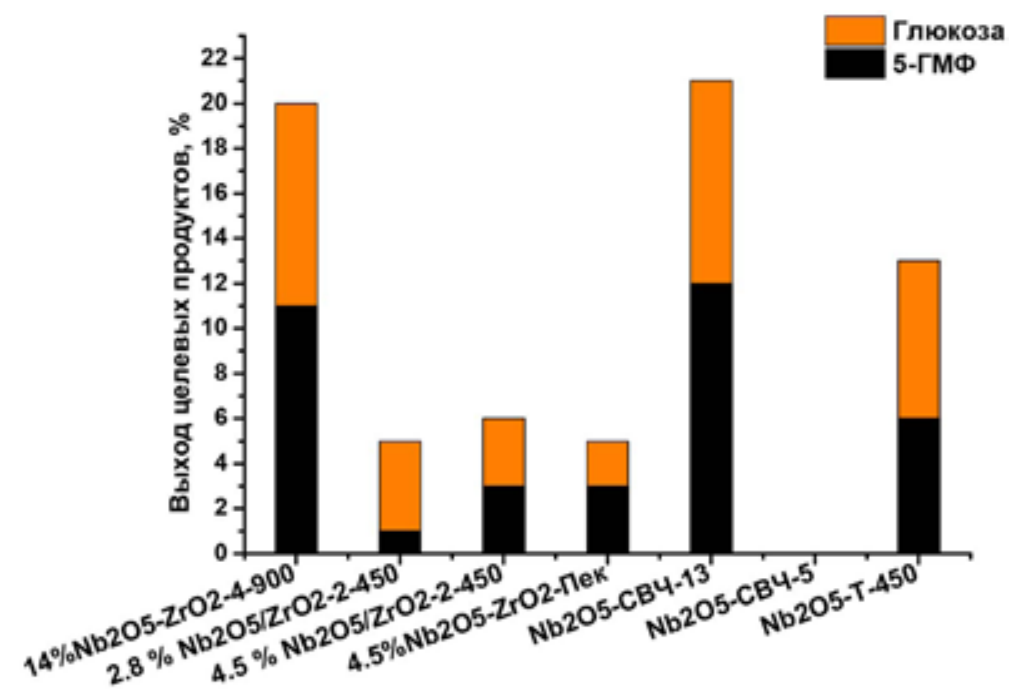

Рис. 2. Результаты каталитических испытаний оксидных катализаторов, приготовленных различными методами, в процессе гидролиза-дегидратации целлюлозы. Условия реакции: $180^{\circ} \mathrm{C}, 10$ атм аргона, 10 г/л катализатора, 10 г/л целлюлозы

Fig. 2. The results of cellulose hydrolysis-dehydration over oxide materials prepared by different techniques. Experimental conditions: $180^{\circ} \mathrm{C}, 10$ bar of argon, catalyst concentration $10 \mathrm{~g} / \mathrm{L}$, cellulose concentration $10 \mathrm{~g} / \mathrm{L}$ 
величину удельной поверхности и значение $\mathrm{pH}$ суспензии, близкое к нейтральному. Катализатор на основе оксида ниобия, приготовленный методом СВЧ-обработки в течение 13 мин $\left(\mathrm{Nb}_{2} \mathrm{O}_{5}\right.$-СВЧ-13, образец 3), показал достаточную каталитическую активность в исследуемом процессе. Суммарный выход глюкозы и 5-ГМФ достигал $21 \%$. Аналогичный по составу и методу приготовления катализатор $\mathrm{Nb}_{2} \mathrm{O}_{5}$-СВЧ-5 (образец 2), отличающийся от образца $\mathrm{Nb}_{2} \mathrm{O}_{5}$ СВЧ-13 меньшим временем СВЧ-обработки, оказался практически неактивен. Полученные данные свидетельствуют о выраженном влиянии продолжительности сверхвысокочастотного облучения на активность катализатора. Очевидно, что малые времена обработки, до 5 мин, не позволяют получить материал, активный в гидролизе-дегидратации целлюлозы. Сравнение одинаковых по составу образцов 1 и 3 показывает, что катализатор, приготовленный СВЧобработкой в течение 13 мин, более эффективен по сравнению с катализатором, полученным простым терморазложением предшественника при $450{ }^{\circ} \mathrm{C}$.

Интересно также сравнить эффективность в деполимеризации целлюлозы двухкомпонентных материалов на основе оксидов ниобия и циркония, приготовленных разными методами. Образец 6, $4.5 \% \mathrm{Nb}_{2} \mathrm{O}_{5}-\mathrm{ZrO}_{2}-2-450$, приготовленный мехактивацией предшественников с последующим прокаливанием, показал несколько более высокую активность по сравнению с образцом 7, $4.5 \% \mathrm{Nb}_{2} \mathrm{O}_{5}-\mathrm{ZrO}_{2}$-Пек, приготовленным методом Пекини и имеющим аналогичный состав. Сравнение активности образцов 5 и 6, $2.8 \% \mathrm{Nb}_{2} \mathrm{O}_{5}-\mathrm{ZrO}_{2}-2-450$ и $4.5 \% \mathrm{Nb}_{2} \mathrm{O}_{5}-\mathrm{ZrO}_{2}-2-450$ соответственно, демонстрирует, что увеличение содержания оксида ниобия в двухкомпонентной системе позволяет повысить эффективность катализатора в гидролизе-дегидратации целлюлозы. По сравнению с катализатором $2.8 \% \mathrm{Nb}_{2} \mathrm{O}_{5}-\mathrm{ZrO}_{2}-2-450$ в присутствии $4.5 \% \mathrm{Nb}_{2} \mathrm{O}_{5}$ $\mathrm{ZrO}_{2}-2-450$ наблюдается как больший суммарный выход целевых продуктов, так и более эффективное превращение глюкозы в 5-ГМФ (рис. 2). Для более существенного увеличения эффективности двухкомпонентного катализатора нами приготовлен образец, содержащий 14 \% оксида ниобия (14 \% $\mathrm{Nb}_{2} \mathrm{O}_{5}-\mathrm{ZrO}_{2}-4-900$, образец 4) с использованием метода механической активации с последующим высокотемпературным прокаливанием. Образец $14 \% \mathrm{Nb}_{2} \mathrm{O}_{5}-\mathrm{ZrO}_{2}-4-900$ продемонстрировал высокую эффективность в образовании глюкозы и 5-ГМФ несмотря на незначительную удельную поверхность $\left(7 \mathrm{~m}^{2} / \Gamma\right)$ и значение $\mathrm{pH}$ суспензии, близкое к нейтральному. Достигнутый суммарный выход целевых продуктов (20\%) оказался сопоставим с лучшим катализатором на основе оксида ниобия $\mathrm{Nb}_{2} \mathrm{O}_{5}$-СВЧ-13 (21 \%). Этот результат может свидетельствовать о том, что такие важные для катализа факторы, как удельная площадь поверхности и совокупная кислотность катализатора, не являются важными для процесса гидролиза-дегидратации целлюлозы, происходящего с твердым субстратом в водной среде в присутствии твердого катализатора. Имеется гипотеза об особом механизме каталитических процессов в таких многофазных системах, важное значение в котором играет двойной электрический слой, образующийся в растворе на геометрической поверхности твердых частиц катализатора и субстрата [26]. Изучению факторов, ответственных за активность оксидных катализаторов в данной системе, будет посвящена наша следующая работа.

\section{Заключение}

Проведено исследование гидролиза-дегидратации активированной микрокристаллической целлюлозы в глюкозу и 5-ГМФ. В качестве катализаторов процесса использовались 
оксиды ниобия и двухкомпонентные материалы на основе оксидов ниобия и циркония. Деполимеризация целлюлозы проводилась при $180{ }^{\circ} \mathrm{C}$ в атмосфере аргона. Изучено влияние метода приготовления катализаторов на их активность в исследуемом процессе. Оксид ниобия, приготовленный методом терморазложения, продемонстрировал заметную каталитическую активность. Исследование влияния продолжительности СВЧ-обработки на активность $\mathrm{Nb}_{2} \mathrm{O}_{5}$ позволяет заключить, что малые времена облучения, менее 5 мин, не позволяют получить эффективный катализатор. Катализатор, приготовленный методом СВЧ-обработки в течение 13 мин, более активен по сравнению с катализатором, приготовленным терморазложением при $450{ }^{\circ} \mathrm{C}$. Исследование эффективности двухкомпонентных катализаторов на основе оксидов ниобия и циркония показало, что метод Пекини малоэффективен. Метод механической активации предшественников позволяет создавать эффективный катализатор гидролиза-дегидратации целлюлозы. Активность двухкомпонентного катализатора возрастает с увеличением доли оксида ниобия в образце. Наиболее эффективные катализаторы: однокомпонентный образец, полученный СВЧ-обработкой в течение 13 мин; двухкомпонентный - смешанный оксид ниобия и циркония, полученный методом мехактивации предшественников. В присутствии указанных катализаторов глюкоза и 5-ГМФ могут быть получены с суммарным выходом 20-21 \%. Эти данные позволяют сделать вывод о том, что наиболее перспективными методами приготовления твердых катализаторов гидролиза-дегидратации целлюлозы в глюкозу и 5-ГМФ на основе оксидов ниобия и циркония являются способы терморазложения, СВЧ-обработки и механической активации.

\section{Благодарности / Acknowledgements}

Работа выполнена при финансовой поддержке Российского фонда фундаментальных исследований (грант 17-53-16027).

This work was conducted with financial support of Russian Foundation for Basic Research (grant 17-53-16027).

\section{Список литературы / References}

1. Bhaumik P., Dhepe P.L. Solid acid catalyzed synthesis of furans from carbohydrates. Catalysis Reviews 2016. Vol. 58(1), P. 36-112.

2. Murzin D., Salmi T. Catalysis for Lignocellulosic Biomass Processing: Methodological Aspects. Catalysis Letters 2012. Vol. 142(6), P. 676-689.

3. Van de Vyver S., Geboers J., Jacobs P.A., Sels B.F. Recent Advances in the Catalytic Conversion of Cellulose. ChemCatChem 2011. Vol. 3, P. 82-94.

4. van Putten R.-J., van der Waal J.C., de Jong E., Rasrendra C.B., Heeres H.J., Vries J.G. Hydroxymethylfurfural. A Versatile Platform Chemical Made from Renewable Resources. Chemical Reviews 2013. Vol. 113(3), P. 1499-1597.

5. Besson M., Gallezot P., Pinel C. Conversion of Biomass into Chemicals over Metal Catalysts. Chemical Reviews 2014. Vol. 114(3), P. 1827-187.

6. Xue Z., Ma M.-G., Li Z., Mu T. Advances in the conversion of glucose and cellulose to 5-hydroxymethylfurfural over heterogeneous catalysts. RSC Advances 2016. Vol. 6(101), P. 9887498892. 
7. Mariscal R., Maireles-Torres P., Ojeda M., Sádaba I., López Granados M. Furfural: a renewable and versatile platform molecule for the synthesis of chemicals and fuels. Energy \& Environmental Science 2016. Vol. 9(4), P. 1144-1189.

8. Gallezot P. Conversion of biomass to selected chemical products. Chemical Society Reviews 2012. Vol. 41(4), P. 1538-1558.

9. Heinze T. Chemical Functionalization of Cellulose. in: Polysaccharides. Structural diversity and functional versatility. Second edition. Under Ed. Severian Dumitriu. New York: Marcel Dekker, 2005. P. 551.

10. Mukherjee A., Dumont M.-J., Raghavan V. Review: Sustainable production of hydroxymethylfurfural and levulinic acid: Challenges and opportunities. Biomass and Bioenergy 2015. Vol. 72, P. 143-183.

11. Perez S., Mazeau K. Confirmations, Structures, and Morphologies of Cellulose. in: Polysaccharides. Structural diversity and functional versatility. Second edition. Under Ed. Severian Dumitriu. New York: Marcel Dekker, 2005. P. 41-64.

12. Onda A., Ochi T., Yanagisawa K. Hydrolysis of Cellulose Selectively into Glucose Over Sulfonated Activated-Carbon Catalyst Under Hydrothermal Conditions. Topics in Catalysis 2009. Vol. 52(6), P. 801-807.

13. Shuai L., Pan X. Hydrolysis of cellulose by cellulase-mimetic solid catalyst. Energy \& Environmental Science 2012. Vol. 5, P. 6889-6894.

14. Nandiwale K.Y., Galande N.D., Thakur P., Sawant S.D., Zambre V.P., Bokade V.V. One-Pot Synthesis of 5-Hydroxymethylfurfural by Cellulose Hydrolysis over Highly Active Bimodal Micro/ Mesoporous H-ZSM-5 Catalyst. ACS Sustainable Chemistry \& Engineering 2014. Vol. 2(7), P. 19281932.

15. Chambon F., Rataboul F., Pinel C., Cabiac A., Guillon E., Essayem N. Cellulose hydrothermal conversion promoted by heterogeneous Brønsted and Lewis acids: Remarkable efficiency of solid Lewis acids to produce lactic acid. Applied Catalysis B: Environmental 2011. Vol. 105(2), P. 171-181.

16. Wang H., Zhang C., He H., Wang L. Glucose production from hydrolysis of cellulose over a novel silica catalyst under hydrothermal conditions. Journal of Environmental Sciences 2012. Vol. 24(3), P. 473-478.

17. Pang J., Wang A., Zheng M., Zhang T. Hydrolysis of cellulose into glucose over carbons sulfonated at elevated temperatures. Chemical Communications 2010. Vol. 46, P. 6935-6937.

18. Kobayashi H., Komanoya T., Hara K., Fukuoka A. Water-tolerant mesoporous-carbonsupported ruthenium catalysts for the hydrolysis of cellulose to glucose. ChemSusChem 2010. Vol. 3(4), P. 440-443.

19. Gromov N.V., Taran O.P., Semeykina V.S., Danilova I.G., Pestunov A.V., Parkhomchuk E.V., Parmon V.N. Solid Acidic $\mathrm{NbO}_{\mathrm{x}} / \mathrm{ZrO}_{2}$ Catalysts for Transformation of Cellulose to Glucose and 5-Hydroxymethylfurfural in Pure Hot Water. Catalysis Letters 2017. Vol. 147(6), P. 1485-1495.

20. Chareonlimkun A., Champreda V., Shotipruk A., Laosiripojana N. Reactions of C5 and C6sugars cellulose and lignocellulose under hot compressed water $(\mathrm{HCW})$ in the presence of heterogeneous acid catalysts. Fuel 2010. Vol. 89(10), P. 2873-2880.

21. Пестунов А.В., Кузьмин А.О., Яценко Д.А., Правдина М.Х., Таран О.П. Механическая активация чистой и содержащейся в древесных опилках целлюлозы в мельницах различ- 
ного типа. Журнал Сибирского федерального университета. Химия 2015. Т. 8(3), С. 386-400. [Pestunov A.V., Kuzmin A.O., Yatsenko D.A., Pravdina M.H., Taran O.P. The Mechanical Activation of Crystal and Wooden Sawdust Cellulose in Various Fine-Grinding Mills. Journal of Siberian Federal University: Chemistry 2015. Vol. 8. N. 3, P. 386-400. (In Russ.)]

22. Аввакумов Е.Г. Механические методы активации химических процессов. Новосибирск: Наука, 1986. 305 с. [Avvakumov E.G. Mechanical methods for the activation of chemical processes. Novosibirsk: Nauka, 1986. 305 p. (In Russ.)]

23. Patent 3330697A US. Pechini M.P. Method of preparing lead and alkaline earth titanates and niobates and coating method using the same to form capacitor. Publ. Date 11.07.1967.

24. Gromov N.V., Medvedeva T.B., Taran O.P., Bukhtiyarov A.V., Aymonier C., Prosvirin I.P., Parmon V.N. Hydrothermal Solubilization-Hydrolysis-Dehydration of Cellulose to Glucose and 5-Hydroxymethylfurfural Over Solid Acid Carbon Catalysts. Topics in Catalysis 2018. Vol. 61(18-19), P. 1912-1927.

25. Gromov N.V., Medvedeva T.B., Taran O.P., Timofeeva M.N., Said-Aizpuru O., Panchenko V.N., Gerasimov E.Yu., Kozhevnikov I.V., Parmon V.N. The Main Factors Affecting the Catalytic Properties of $\mathrm{Ru} / \mathrm{Cs}-\mathrm{HPA}$ Systems in One-Pot Hydrolysis-Hydrogenation of Cellulose to Sorbitol. Applied Catalysis A: General 2020. Vol. 595, P. 117489.

26. Tarabanko N., Tarabanko V.E., Kukhtetskiy S.V., Taran O.P. Electrical Double Layer as a Model of Interaction between Cellulose and Solid Acid Catalysts of Hydrolysis. ChemPhysChem 2019. Vol. 20(5), P. 706-718. 